Thus, equally plausible assumptions can lead to widely divergent results, and the available experimental data offer as yet little empirical guidance. These chapters include a brief discussion of the more important aspects of the statistical approach to turbulence and a very inadequate reference to the important topic of jet noise. An interesting chapter follows on the mixing of jets of different gases where diffusion becomes important, and the last two chapters deal with the stability of jets of incompressible and compressible fluids. The theory is presented in some detail, but more might have been made of the results. In an appendix the fundamental cquations of fuid dynamics are briefly derived.

The writing lacks grace, and there is an irritating economy in the use of the definite article as well as an occasional misprint. Nevertheless, the book is clearly and honestly presented and should be welcomed by the many aeronautical scientists concerned. with jet flow.

A. D. Young

\section{ENERGY FROM THE SUN}

\section{Applied Solar Energy Research}

A Directory of World Activity and Bibliography of Significant Literature. Edited by E. J. Burda. Pp. ix +298. (Stanford, Calif.: Stanford Research Institute, 1955. Published for the Association for Applied Solar Energy.) n.p.

D ESEARCH on the utilization of solar energy has been greatly stimulated during recent years, and rapid developments have been made in the United States and other countries. There is an increasing realization that such applications will play an important part in the future co-ordination of world energy resources, and an Association for Applied Solar Energy has been formed at Phoenix, Arizona. As a preliminary stage in its programme to encourage research, this Association has issued the first international directory and bibliography of solar research as a record of what has been done in the past and is being attempted in the present.

This publication is much more than a mere list of references; under headings of countries, Part 1 lists the universities, other organizations and individual research workers who are engaged in solar energy activities, with brief summaries of the work in progress. Although the United States section contains more entries than all other countries together, there is evidence of an active world-wide interest in this subject. Short details are given of solar symposia that have been held since 1950, including particulars of the World Symposium on Applied Solar Energy which is to be held this November in Phoenix, Arizona.

Part 2, constituting the remainder of the volume, is a bibliography containing nearly fifteen hundred references, with short abstracts in most cases. These references are numbered and arranged in alphabetical order ; and the numbers are rearranged in a crossreierence of classified subjects-for example, distillation, heaters, insolation, photo-synthesis, to give a few examples. The information is invaluable not only to those engaged in active research, but also to those commencing a study of the subject. Library facilities and staff for this publication were provided by the Stanford Research Institute under the general direction of Merritt L. Kastens, with the co-operation of Dr. Marie Telkes, of New York University.

\section{H. HEYwood}

\section{TECHNOLOGY OF TITANIUM}

Titanium in Industry

Technology of Structural Titanium. By Stanley Abkowitz, John J. Burke and Ralph H. Hiltz, Jr. Pp. $x+224$. (New York: D. Van Nostrand Company, Inc.; London: Macmillan and Co., Ltd., 1955.) 36s. net.

7 HE development of the three structural metals

of this scientific age-titanium, magnesium and aluminium-has not, in terms of the span of human life, been fast. In each of these cases, from being initially recognized in the laboratory, until equal recognition was attained in the industrial world, a period of time varying from three-quarters to rather more than a century and a half has elapsed. Seemingly, but not paradoxically, because the metallurgical difficulties involved were very great, titanium, the first of this little group to be discovered, has taken longer to acquire engineering status than the other two. In 1789 , its existence was clearly realized by the Rev. William Gregor. The metal did not, however, attain a position in engineering until the present decade. It-or more exactly, some of its alloys-was then shown to have a combination of qualities, such as low specific gravity when compared with iron; mechanical properties (up to about $300^{\circ} \mathrm{C}$.) comparable with those of alloy steels; and, in a large number of media and in particular in sea water, a quite outstanding resistance to corrosion. These characteristics made it suitable for applications where performance, rather than cost, was the primary consideration. This is, of course, the case in the aircraft gas-turbine field.

In a book of slightly more than two hundred pages, divided into ten chapters, the authors attempt to cover the production of the metal, its chemistry and physics, and manipulation in mill, forge and workshop of both it and of some of its many alloys. The task they have thus undertaken is a formidable one. Their book is of necessity superficial. It is not, however, inaccurate, and indeed has merit. It contains more than twenty excellent photomicrographs and some good graphs in relation to a number of the mechanical properties of some of the many titanium alloys. With regard to their fatigue and creep characteristics, however, the treatment is disappointing. This is unfortunate, for it is these qualities which are of the utmost importance in the field in which the metal and its alloys are at present finding their greatest application. Against this criticism, it is but fair to state that the work is, in most respects, up to date. For example, the authors disclose, as has only recently been appreciated, the unexpected but tremendous influence of hydrogen on titanium. In excess of a hundred parts per million, this gas, which markedly alters the microstructure of the metal, is deleterious. When the metal contains double this amount, a number of undesirable characteristics, for example, grave reduction in such essen. tial engineering properties as ductility, impact and fatigue resistance, may well arise.

To conclude : anyone having a somewhat detached interest in titanium and its alloys will find this wellproduced book, in spite of its relatively high cost, a worthwhile introduction to a very large subject. On the other hand, should the potential reader be already involved in the production and/or use of titanium and its alloys for structural and/or mechanical purposes, it will often prove wanting - due to the magnitude of its scope, it inevitably lacks depth. P. L. TeED 